\title{
Occurrence of marked sepsis-induced immunosuppression in pediatric septic shock: a pilot study
}

\author{
Solenn Remy ${ }^{1} \mathbb{0}$, Karine Kolev-Descamps ${ }^{1}$, Morgane Gossez ${ }^{2}$, Fabienne Venet ${ }^{2,3}$, Julie Demaret ${ }^{2}$,
} Etienne Javouhey ${ }^{1}$ and Guillaume Monneret $2,3^{*}$

\begin{abstract}
Background: While the process of sepsis-induced immunosuppression is now well described in adults, very little information is available on immune functions in pediatric sepsis. The current study investigated this in children with septic shock by performing immunomonitoring, including both innate (monocyte human leukocyte antigen$\mathrm{DR}, \mathrm{mHLA}-\mathrm{DR}$, expression) and adaptive immunity (lymphocyte subsets count), as well as cytokine concentrations (IL-6, IL-8, IL-10, IL-1Ra, TNF-a, IFN- $)$ ). Subsequent objectives were to assess the associations between inflammatory response, potential immunosuppression and secondary acquired infection occurrence.
\end{abstract}

Methods: Single-center prospective observational study, including children aged between 1 month and 18 years admitted to pediatric intensive care unit (PICU) for septic shock. Age-matched controls were children hospitalized for elective surgery without any infectious criteria. Blood was sampled at day 1-2, 3-5, and 7-9 after sepsis onset. mHLA-DR and lymphocyte subsets count were measured by flow cytometry and cytokine concentrations by Luminex technology.

Results: A total of 26 children and 30 controls were included. Patients had lymphopenia, and mHLA-DR levels were significantly lower than controls at each time point $(p<0.0001)$. All cytokines peaked at day $1-2$. Children with secondary acquired infection had lower day 3-5 mHLA-DR and higher pro-inflammatory cytokine concentrations (IL-6, IL-8 and TNF-a) at day 1-2 compared to children without secondary acquired infection.

Conclusions: The higher initial inflammatory cytokine production was, the more innate immunity was altered, while evaluated by low mHLA-DR expression. Children with decreased mHLA-DR expression developed more secondary acquired infections. Upon confirmation in multicenter cohorts, these results pave the way for immunostimulation for the most immunosuppressed children in order to prevent nosocomial infections in PICU.

Trial registration PedIRIS study NCT02848144. Retrospectively registered 28 July 2016

Keywords: Septic shock, Immunosuppression induced, Children

\section{Background}

Despite advances in critical care management, septic shock remains one of the most important causes of mortality and morbidity in children worldwide [1]. As for adults, the inability of adjunctive therapies to mitigate

\footnotetext{
*Correspondence: guillaume.monneret@chu-lyon.fr

${ }^{2}$ Hospices Civils de Lyon, Immunology Laboratory, E. Herriot Hospital, 69003 Lyon, France

Full list of author information is available at the end of the article
}

the deleterious effects of this condition indicates that it is likely that initial hypotheses for sepsis pathophysiology have been inadequately addressed [2]. In adults, it is now agreed that sepsis deeply perturbs immune balance by inducing a strong systemic inflammatory response and a concomitant anti-inflammatory process, acting as a negative feedback. This compensatory response may secondarily become harmful as most immune functions are compromised, and thus sepsis-induced immune alterations may play a major role in the decreased resistance 
to secondary acquired infections in patients who initially survive [3]. This immunosuppressive state is characterized by both abnormal innate and adaptive immune responses. In particular, patients mostly present with marked lymphopenia and decreased expression in monocyte human leukocyte antigen-DR (mHLA-DR). The latter remains, to date, the key parameter of patient monitoring and its diminished expression has been reported to be associated with increased mortality and nosocomial infection rate in adults [4-6]. In this context, and as it is already the case for cancer immunotherapy, targeted treatments aimed at rejuvenating immune responses in adult septic patients (e.g., GM-CSF, Interleukin-7, antiPD-1/-L1) are now envisaged [7-10]. In comparison with adults, data are very scarce in children with septic shock. The impact of this altered immune response on secondary infections is poorly reported in children affected by septic shock. In order to envisage therapeutic interventions to restore immune function in children, a reliable biomarker is required to identify children at highest risk of secondary acquired infection or mortality. Such a marker is currently lacking in children. Most pediatric results are rarely specific of septic shock. They refer, as a whole, to various pediatric intensive care unit (PICU) admission causes (surgery, organ dysfunctions) [11-14], or are limited to particular cases of preterm neonates $[15,16]$. Thus, the objective of the present prospective observational study was to investigate whether pediatric septic shock patients present immune alterations similar to those seen in adults. For this, immunomonitoring was performed during the first week after sepsis onset. This monitoring included mHLA-DR, lymphocyte subsets count, and phenotyping as well as measurement of plasma cytokine concentrations: interleukin-6 (IL-6), interleukin-8 (IL-8), interleukin-10 (IL-10), tumor necrosis factor- $\alpha$ (TNF- $\alpha)$, interferon- $\gamma$ (IFN- $\gamma)$, and interleukin-1 receptor antagonist (IL-1Ra). As control values may depend on age, and in the absence of mHLA-DR reference range in pediatrics, healthy children were also investigated to explore mHLA-DR expression during the first years of life.

\section{Methods}

\section{Study population}

This single-center, prospective study was held in PICU from a tertiary academic hospital (23 beds mixed medical-surgical unit, $>1100$ admissions/year). Children, aged from 1 month to 18 years, were included prospectively during $24 \mathrm{~h}$ of PICU admission, if they presented septic shock, defined by "Surviving Sepsis Campaign" and Goldstein's criteria [17, 18]. Exclusion criteria were: non-septic shock, chronic inflammatory disease, longterm corticosteroid treatment, transplantation and/or immunosuppressive therapy, immunodeficiency syndrome, malignant tumors. Opposition from the child and/or parent/holder of parental authority also constituted exclusion criteria. Controls were age-matched to the case group and identified among outpatients admitted for a scheduled surgery, without any criteria of infection. Exclusion criteria were the same as the case group. Three age subgroups were defined: 1 month to 2, 2-8, and $>8$ years, according to the physiological age-based development of immunity in children [19].

\section{Clinical data and definitions}

Clinical data were collected prospectively and obtained from the electronic medical record. At admission (day 1), severity of illness was evaluated using the pediatric index of mortality 2 (PIM2) [20]. Organ failure was assessed by the measurement of PEdiatric Logistic Organ Dysfunction Score, version 2 (PELOD-2) at day 1, 3, and 7 [21]. Vasoactive treatments during hospitalization in PICU were determined by the cumulative vasopressor index (CVI) [22]. We also collected incidence of secondary acquired infection, mortality (death occurring within 28 days after the onset of shock), number of mechanical ventilation-free days, and number of PICU-free days in the first 30 days. Secondary acquired infection was defined by Center for Disease Control criteria, included any new bacterial or fungal infection, distinct from initial infection, occurring more than $48 \mathrm{~h}$ after sepsis onset, during the first 30 days after sepsis onset [23]. Determination of secondary acquired infection was performed prospectively by one physician (SR), blinded to immunological data.

\section{Blood sampling for immunomonitoring}

Blood samples were collected within the first $48 \mathrm{~h}$ after the onset of infection, again between day $3-5$, and day 7-9. Samples were not available if patients were no longer in PICU. Blood was collected in EDTA tubes, transported rapidly at $4{ }^{\circ} \mathrm{C}$ to the Cellular Immunology Laboratory, and analyzed within less than $4 \mathrm{~h}$. The amount of blood sample did not exceed $2.4 \mathrm{ml} / \mathrm{kg}$, in accordance with European recommendations. At each time point, the following parameters were determined by flow cytometry: mHLA-DR, total lymphocytes and lymphocytes subpopulations $\left(\mathrm{CD} 4^{+}\right.$and $\mathrm{CD} 8^{+} \mathrm{T}$ cells, natural killer $[\mathrm{NK}]$ cells, regulatory $\mathrm{T}$ cells [Treg], and $\mathrm{B}$ cells). In addition, after completion of cellular analysis, plasma was obtained after centrifugation and stored at $-80^{\circ} \mathrm{C}$ for subsequent quantification of following circulating cytokines: IL-6, IL-8, IL-10, IL-1RA, TNF- $\alpha$, and IFN- $\gamma$. For the control group, blood was sampled in the operating room immediately after induction of general anesthesia with sevoflurane, before start of surgery. 


\section{Flow cytometry}

Quantification of mHLA-DR on circulating monocytes was performed using a standardized flow cytometric assay as previously described [24.] The median fluorescence intensity of the entire monocyte population was then transformed to number of antibodies bound per cell $(\mathrm{ABC})$ using calibrated PE beads (BD QuantiBRITE ${ }^{\mathrm{TM}} \mathrm{PE}$ Beads, Becton-Dickinson San Jose, CA, USA). The following lymphocyte subsets were analyzed by flow cytometry as previously described $[25,26]$ : total $\mathrm{T}$ lymphocytes $\left(\mathrm{CD} 45^{+} \mathrm{CD}^{+}\right), \mathrm{CD}^{+} \mathrm{T}$ lymphocytes $\left(\mathrm{CD} 45^{+} \mathrm{CD} 4^{+}\right.$ $\left.\mathrm{CD}^{+}\right), \mathrm{CD}^{+} \mathrm{T}$ lymphocytes $\left(\mathrm{CD} 45^{+} \mathrm{CD}^{+} \mathrm{CD}^{+}\right)$, total B cells $\left(\mathrm{CD} 45^{+} \mathrm{CD} 19^{+}\right)$, NK cells $\left(\mathrm{CD} 45^{+} \mathrm{CD} 3^{-}\right.$ $\left.\mathrm{CD} 6^{+}\right)$, and Treg $\left(\mathrm{CD} 4^{+} \mathrm{CD} 25^{+} \mathrm{CD} 127^{-}\right)$. Results were expressed as numbers of cells per microliter of blood for lymphocyte subsets and as percentage of positive cells among total $\mathrm{CD} 4^{+}$lymphocyte population for Treg.

\section{Cytokine measurement}

IL-6, IL-8, IL-10, IL-1RA, TNF- $\alpha$, and IFN- $\gamma$ were quantified with a single panel (Milliplex ${ }^{\circledR}$ MAP Human Cytokine/Chemokine Magnetic Bead Panel, Merck Millipore) using the fluorescent bead-based multiplexed Luminex xMAP technology [27]. Analyses were performed on Bio-Plex 200 Luminex instrument using BioPlex software (Bio-Rad, Hercules, CA, USA).

\section{Statistical analysis}

Results are expressed as median and interquartile range [IQR]. Comparisons between groups were analyzed using the Man-Whitney $U$ test for continuous nonparametric variables; the independent paired $t$ test for continuous parametric variables and the Chi-square test for categorical data. Correlation analyses were performed using the Pearson test for variables following a normal distribution, and Spearman for nonparametric variables. KaplanMeier analyses were performed using Youden's index to stratify groups of patients. A $p$ value $<0.05$ was considered to represent significant statistical difference. Data were analyzed by using Prism6 software (GraphPad Inc., La Jolla, CA, USA).

\section{Results}

\section{Subjects}

Between September 2014 and July 2016, 73 children were screened for septic shock. Among these, 47 were excluded (toxic shock syndrome, non-infectious shock, known immunosuppression, or chronic inflammatory disease). A total of 26 children were included and analyzed (Fig. 1). Demographic data are presented in Table 1. Nine children (35\%) presented a complex chronic condition. The most frequent was prematurity $(n=4)$, but all children presented a corrected age greater than 1 month.

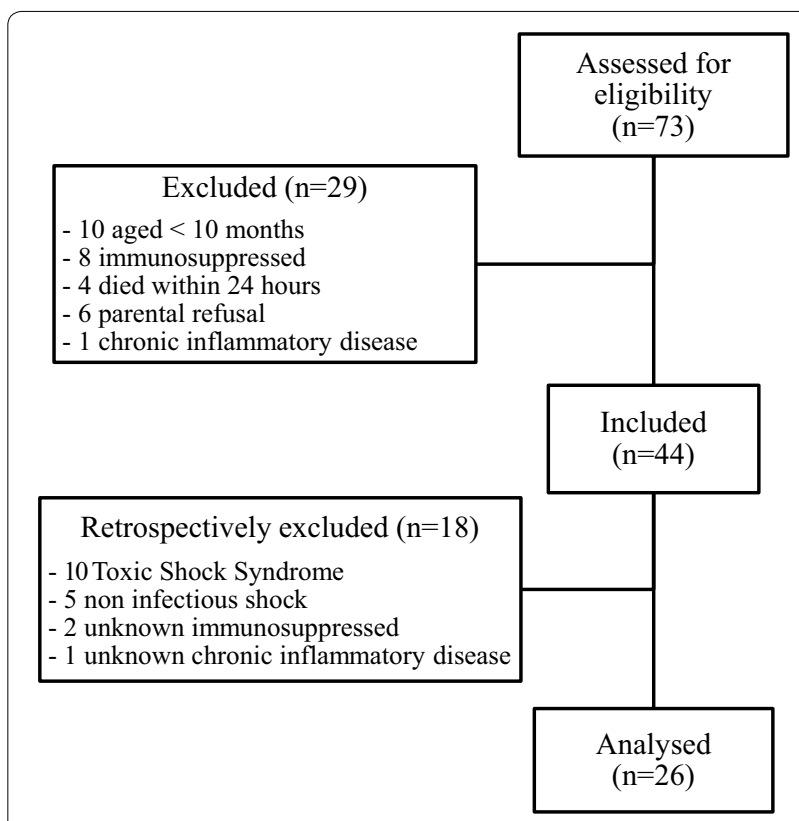

Fig. 1 Flowchart

Others presented psychomotor delay $(n=2)$, polymalformative disease $(n=2)$, and sickle cell disease $(n=1)$. Two children died: one precociously at day 2 , due to refractory shock with multi-organ failure; and the second one at day 32, with withdrawal treatment for major brain damage after meningitis. A total of 30 healthy children were included as controls. They were age-matched with children in septic shock ( $p=0.3$, Mann-Whitney): 11 were aged between 1 month and 2 years, 14 between 2 and 8 years, and $5>8$ years.

\section{mHLA-DR expression}

In healthy control children, mHLA-DR was $>25,000$ $\mathrm{ABC}$; among those aged between 1 month to 2 years it was (median [IQR]) 25,477 ABC [20,478-39,143], among those aged $2-8$ years it was $34,295 \mathrm{ABC}[25,763-43,368]$, and among those older than 8 years it was $29,597 \mathrm{ABC}$ [26,636-41,939]; there was no significant difference between age subgroups $(p=0.35$; ANOVA, Fig. 2a). There was also no correlation between age and mHLA$\mathrm{DR}(r=0.018)$.

In children with septic shock, mHLA-DR was 6066 $\mathrm{ABC}[3737-16,310]$ at day 1-2, $6308 \mathrm{ABC}$ [3185-8965] at day 3-5, and $9323 \mathrm{ABC}[6384-12,738]$ at $7-9$; at each time point values were significantly different to that found in healthy control children $(p<0.0001$; Fig. $2 \mathrm{~b})$. There was no correlation between mHLA-DR and PIM2 or PELOD-2 scores, at any time point, while a significant correlation was found between day 3-5 mHLA-DR and CVI $(r=-0.50 ; p=0.031$; Fig. 2c). 
Table 1 Characteristics of the 26 children with septic shock included in the study

\begin{tabular}{|c|c|}
\hline & Septic shock $(n=26)$ \\
\hline Age (years) & $2.12[0.47-4.60]$ \\
\hline Male gender [n (\%)] & $11(42)$ \\
\hline Complex chronic conditions [n (\%)] & $9(35)$ \\
\hline Primary nosocomial infection & $1(3.9)$ \\
\hline \multicolumn{2}{|l|}{ Site of initial infection [n (\%)] } \\
\hline Blood & $3(11.5)$ \\
\hline Lung & $4(15.4)$ \\
\hline Abdomen & $8(30.8)$ \\
\hline Multi-site & $9(34.6)$ \\
\hline Others & $1(3.9)$ \\
\hline No documentation & $1(3.9)$ \\
\hline \multicolumn{2}{|l|}{ Microbiology } \\
\hline \multicolumn{2}{|l|}{ Gram-negative bacteria } \\
\hline Neisseria meningitidis & $8(30.8)$ \\
\hline Escherichia coli & $3(11.5)$ \\
\hline Klebsiella species & $2(7.7)$ \\
\hline Enterobacter species & $2(7.7)$ \\
\hline Campylobacter jejuni & $1(3.8)$ \\
\hline Haemophilus influenzae & $1(3.8)$ \\
\hline \multicolumn{2}{|l|}{ Gram-positive bacteria } \\
\hline Streptococcus pneumoniae & $3(11.5)$ \\
\hline Streptococcus pyogenes & $2(7.7)$ \\
\hline Staphylococcus aureus & $1(3.8)$ \\
\hline \multicolumn{2}{|l|}{ Viruses } \\
\hline Parainfluenzae virus & $1(3.8)$ \\
\hline PIM2 admission (\%) & $8.1[3.2-17.4]$ \\
\hline \multicolumn{2}{|l|}{ PELOD-2 } \\
\hline Day 1 & $9.5[2.75-12.0]$ \\
\hline Day 3 & $4.0[0.0-10.0]$ \\
\hline Day 7 & $0.0[0.0-5.0]$ \\
\hline CVI & $4.0[0.0-7.0]$ \\
\hline ICU-free days in 30 days & $23.0[19.0-26.0]$ \\
\hline Secondary acquired infections [n (\%)] & $8(30)$ \\
\hline Mortality [n (\%)] & $2(7)$ \\
\hline
\end{tabular}

Values are expressed as median [interquartile range], or a number (percentage) PIM2 pediatric index of mortality 2, PELOD-2 PEdiatric Logistic Organ Dysfunction score, version 2, CVI cumulative vasopressor index

\section{Cytokines}

For all cytokines, maximal elevated values were measured on early time point. Then, they presented a gradual decrease on following days but remained significantly elevated in comparison with normal values (Table 2). At day 1-2, IL-6 and IL-8 levels were significantly correlated with PELOD-2 $(r=0.52, p=0.012$ and $r=0.43$, $p=0.048$, respectively) and with CVI $(r=0.65, p=0.001$ and $r=0.51, p=0.015$, respectively). No correlation between initial cytokines concentrations and PIM2 score was found. Also, there was no correlation between initial cytokines levels and mHLA-DR at day 1-2. However, IL-8, IL-10, IL-1ra and TNF- $\alpha$ levels at day 1-2 were significantly negatively correlated with mHLA-DR at day $3-5(r=-0.84, p<0.0001 ; r=-0.59, p=0.0198$; $r=-0.58, p=0.023 ; r=-0.69, p=0.0042$, respectively).

\section{Lymphocyte subsets}

Lymphocyte subsets from healthy control children are presented in Table 3. Among septic patients the total lymphocyte count was significantly lower than in healthy control children at day $1-2$ and day 3-5; there was no significant difference at day 7-9 (Fig. 3a). Similar results were observed for $\mathrm{CD}^{+}$(Fig. $3 \mathrm{~b}$ ) and $\mathrm{CD}^{+} \mathrm{T}$ cell (Fig. 3c) subsets. The median total NK cell count was significantly lower as compared to healthy control children over the whole monitoring period (Fig. 3d). In contrast and, although diminished, B cells were modestly affected (Fig. 3e). The median proportion of Treg was initially similar to that found in healthy control children; this increased at day 3-5, and became significantly greater at day 7-9 (Fig. 3f). Of note, we did not find any correlation between lymphocytes subsets and CVI (data not shown).

\section{Secondary acquired infections}

A secondary acquired infection was diagnosed in eight children (Additional file 1: Tables S1 and S2). The median time to onset of these infections was 13.5 days (range: [9-25]). Compared to children who did not developed secondary acquired infection, the sole difference was a longer length of hospital stay for children who presented secondary acquired infection $(p=0.009$; Additional file 1 : Table S1). Between these two groups, no difference was observed concerning duration of invasive equipment, PICU staying, complex chronic condition and severity scores. No significant difference in lymphocyte subset was observed between children with or without secondary acquired infections. No association was found between persistent lymphopenia (defined as an absolute lymphocyte count of $<1000$ cells $/ \mu$ for 3 days) and development of secondary acquired infection. At day 1-2, there was no significant difference in mHLA-DR values; at day 3-5 those with secondary acquired infection had a significantly lower level of mHLA-DR (4398 ABC [24376212]) than those without (8474 ABC [5904-10,844], $p=0.022$; Fig. 2d). At day 1-2, children with secondary acquired infection had higher concentrations of IL-6, IL-8, and TNF-a than those without (Additional file 1: Table S1). There was no significant difference in cytokine concentrations at other time points. The area under the curve from receiver operating curve (ROC) analysis for the risk to develop a secondary acquired infection were all significantly $>0.8$ for these four significant parameters 

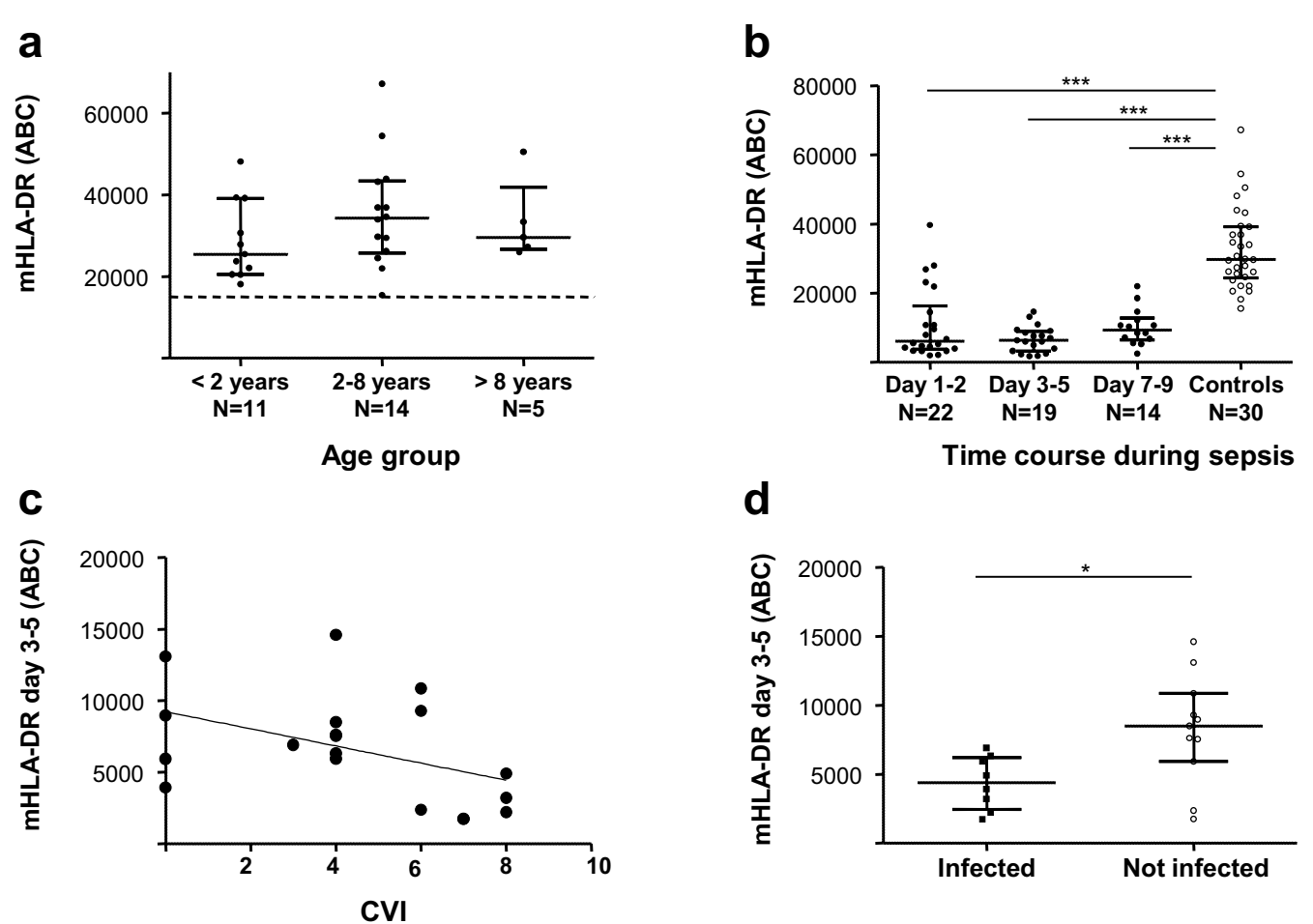

Fig. 2 mHLA-DR measurements in pediatric septic shock. a mHLA-DR expression in healthy children: no difference according to age groups $(p=0.35$; ANOVA). Dashed line depicts usual threshold to define normal values in adults. b mHLA-DR was significantly decreased at each time point during septic shock, than controls ( $p<0.001$; Mann-Whitney). c mHLA-DR at day 3-5 was significantly negatively correlated with cumulative vasopressor index, CVI ( $r=-0.50 ; p=0.031$; Spearman). $\mathbf{d}$ mHLA-DR was significantly lower in children with secondary acquired infection than those without ( $p=0.022$; Student $t$ test)

Table 2 Plasma cytokines levels from healthy children and children with septic shock

\begin{tabular}{|c|c|c|c|c|}
\hline & \multirow[t]{2}{*}{ Healthy controls } & \multicolumn{3}{|c|}{ Children with septic shock } \\
\hline & & Day 1-2 & Day 3-5 & Day 7-9 \\
\hline IL-6 & $0.0[0.0-0.36]$ & $178.5[25.77-3311]$ & 18.13 [12.92-172.5] & $17.97[3.30-33.08]$ \\
\hline $\mathbb{I L}-8$ & $2.05[0.43-5.06]$ & 51.72 [19.07-145.7] & $21.45[11.42-56.36]$ & $15.00[7.98-37.98]$ \\
\hline IL-10 & $0.36[0.0-4.44]$ & $43.37[17.11-331.6]$ & $8.26[3.44-21.66]$ & $11.83[1.70-23.73]$ \\
\hline IL1-RA & $0.0[0.0-17.16]$ & $136.9[23.72-647.8]$ & $48.02[0.0-153.2]$ & $56.54[0.0-121.3]$ \\
\hline TNF-a & $4.91[3.35-7.11]$ & $25.13[14.52-40.47]$ & $8.37[5.34-14.62]$ & $10.15[4.10-15.43]$ \\
\hline INF- $\gamma$ & $4.98[1.82-6.45]$ & $15.81[6.55-24.22]$ & $8.07[2.78-11.45]$ & $10.92[4.65-23.70]$ \\
\hline
\end{tabular}

Values $(\mathrm{pg} / \mathrm{ml})$ are expressed as median [IQR]. All cytokine values in children with septic shock at all-time points were different from those of healthy controls

(mHLA-DR at day 3-5, and IL-6, IL-8 and TNF-a at day 1-2, Additional file 1: Table S3). In line with this, mHLADR at day 3-5 was negatively correlated with cytokines (except IFN- $\gamma$ ). Owing to the sample size, no multivariate regression could be performed to test independence between mHLA-DR and cytokines for the prediction of risk of secondary acquired infection occurrence.
We next performed Kaplan-Meier analyses associating mHLA-DR values and each cytokine level separately, which found that children with lowest values of mHLA-DR and highest cytokine levels were significantly more likely to be infected. Those with mHLA-DR above the threshold remained uninfected, independently of cytokine level (Additional file 1: Fig. S1). 


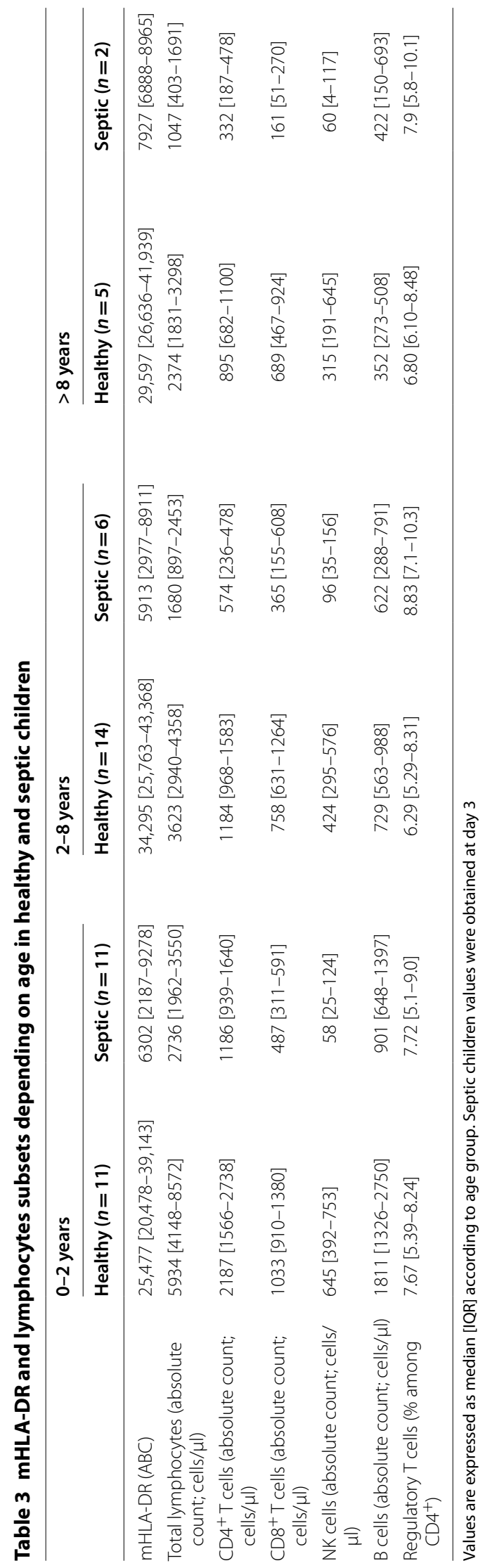



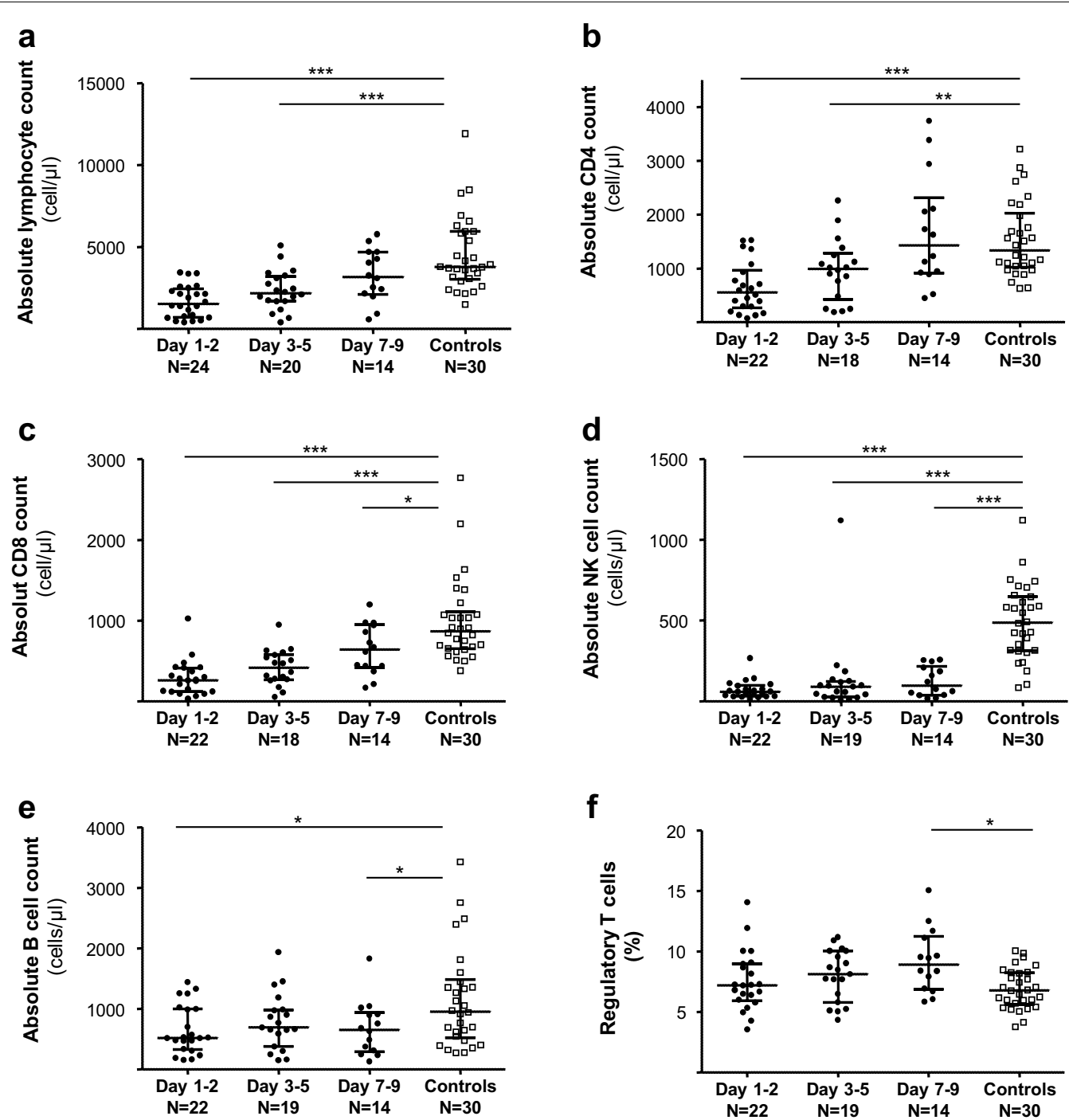

Fig. 3 Time course of lymphocytes' subsets during septic shock. a Total lymphocytes, $\mathbf{b} C D 4^{+} T$ cells, $\mathbf{c} C D 8^{+} T$ cells, $\mathbf{d} \mathrm{NK}$ cells, e B cells (from a to e, results as cell number/ $\mu$ l), f proportion of regulatory T cells (among CD4+lymphocytes). ${ }^{*} p<0.05 ;{ }^{* *} p<0.01 ;{ }^{* * *} p<0.0001$

\section{Discussion}

The present investigation is, to the best of our knowledge, the first prospective pediatric study reporting a wide immune monitoring, specifically in septic shock. However, the first important result of this study is the values of mHLA-DR expression in healthy children. There was no variation according to age (between 6 months and 17 years) and, furthermore, the values are not different to those reported in adults [28]. These results strongly suggest that there is no difference between healthy adults and children in terms of mHLA-DR expression. Important fall in mHLA-DR during pediatric septic shock seems to be similar to those observed during adult septic shock.
The cytokine storm reported herein, involving both pro and anti-inflammatory cytokines, was found in the initial period after shock (day 1-2). At the same time, children who later developed a secondary acquired infection had higher plasma cytokine concentrations (i.e., IL-6, IL-8, and TNF- $\alpha$ ). This is in agreement with observations from genomic studies that have found that early mRNA expression modulations of cytokines and apoptotic genes were associated with deleterious outcomes (mortality, secondary infections) [29,30]. Moreover, to the best of our knowledge, this is the first pediatric study which reported correlation between initial cytokine storm and alteration of innate immunity, represented by loss of mHLA-DR. 
Concerning adaptive immunity, B and T lymphocytes were diminished initially, but less impacted and corrected faster than mHLA-DR alteration. The modest diminution of B cells constitutes a difference with that found in adults, for instance Monserrat et al. [31] described severe abnormality of circulating B lymphocytes associated with mortality. Concerning NK cells, Halstead et al. [32] observed a decrease at the beginning of sepsis in children. The present study provides supplementary data since a deep and prolonged alteration of circulating NK cells was found. Although we did not explore this side, NK cell alterations could promote infections by opportunistic viral pathogens [33]. In contrast with the study reported by Muszynski et al. [14], an increase in Treg proportion during the first week was observed herein. This kinetic seems similar to that described in adult septic shock, where an increased proportion of Treg was associated with poor outcome [34]. Here, as for other lymphocyte parameters, no association with nosocomial infections was found. Additional functional testing (proliferation, intracellular cytokine production) would be likely informative and deserves to be further investigated. At this stage, the present lymphocyte data seem to indicate that altered lymphocyte count rapidly self-resolves, in contrast with observations made in adults.

With regards to innate immunity, loss of mHLADR has emerged as a gold standard biomarker owing to its association with altered monocyte functionality, increased mortality, and nosocomial infection rate after adult septic shock $[6,35]$. In accordance, we report here a significant fall in mHLA-DR in children. Importantly, the lowest values at day 3-5 were found in patients who developed secondary acquired infections. At this time point, all patients with forthcoming infections presented mHLA-DR below 8000 ABC (i.e., the usual threshold for defining the most severely immunosuppressed adult patients [36]). Most pediatric studies have used ex vivo LPS-induced TNF- $\alpha$ production by monocytes to assess innate immunity function. However, Drewry et al. [35] presented recently mHLA-DR as a better predictor of deleterious outcomes than LPS-stimulated TNF- $\alpha$ production. Add to our results, these data reinforced the idea to use mHLA-DR as biomarker of altered innate immunity in pediatric studies. Due to low number of deaths in the present cohort, we did not investigate the potential association with mortality. Although not all obtained using a standardized measurement protocol, the pediatric mHLA-DR data available in the literature are in agreement with that reported herein. For example, Manzoli et al. [13] found the extent of mHLA-DR level reduction during the first week after sepsis onset to be associated with mortality ( $23 \%$ mortality), and Genel et al. [16] also reported lower levels of mHLA-DR among infected neonates who did not survive compared to those who did (20\% mortality). Decreased mHLA-DR has also been described in pediatric surgery and was associated with later sepsis and pneumonia [37, 38]. In addition, Hall et al. [11] reported that, in children with multiple organ dysfunction syndrome, persistent decreased TNF- $\alpha$ release (that reflects monocyte functionality) over 5 days was associated with development of secondary infection. In addition, some in vitro and animal studies suggest potential role of norepinephrine in the development of sepsis-induced immunosuppression [39]. These data reinforced our significant correlation between day 3-5 mHLA-DR and CVI.

Collectively, this indicates that, as in adults, mHLADR presents potential for the identification of the most severe immunosuppressed children. The next step would, of course, be to perform multivariate analysis in a larger patient sample to explore the independence of each parameter in predicting deleterious outcomes. That given, Kaplan-Meier analyses found that although different markers (i.e., day 3-5 mHLA-DR and early elevated cytokines) were associated with secondary acquired infections, the weight of mHLA-DR was more important. Interestingly, as observed in adult trauma patients, association between early cytokines production and low day 3-5 mHLA-DR appeared as the poorest scenario in pediatric septic shock [40].

Furthermore, secondary acquired infections represent a major economic burden by significantly extending length of hospital stay [41, 42], and concordantly herein the length of hospitalization in those with secondary infection doubled (and this difference was significant). Taken together, these data reinforce the idea that most immunosuppressed septic children might benefit from immunostimulation as an adjunctive therapy [43]. Clinical trials are in progress with GM-CSF (NCT02361528) or IL-7 (NCT02640807/NCT02797431) in adults, and standardized tools are currently used to stratify patients in those trials. This progressively paves the way for this kind of approach in pediatrics, especially for innate immunity that seems to be more affected.

The study does, however, have some limitations. First, the relatively small number of included children precluded multivariate analyses to be performed. Second, some children were discharged from PICU before all samples were obtained, and therefore the time course of different immune parameters in less severe children was not determined. Due to the relatively short follow-up period, we cannot conclude on the long-term outcome of these children treated for septic shock. In addition, functional testing should be performed in next studies. Theses aspects need to be further explored, and ideally in a multicenter study. 


\section{Conclusion}

As in adults, septic shock in pediatric patients induced marked alterations in immune parameters in accordance with the occurrence of a state of immunosuppression. The present results, in particular the association between low mHLA-DR expression and deleterious outcomes, deserves to be assessed and confirmed in multicenter studies.

\section{Additional file}

Additional file 1. Online data supplement

\begin{abstract}
Abbreviations
ABC: antibodies bound per cell; CVI: cumulative vasopressor index; IFN- $\gamma$ : interferon- $\gamma$; IL-1Ra: interleukine-1 receptor antagonist; IL-6: interleukine-6; IL-8: interleukine-8; IL-10: interleukine-10; mHLA-DR: monocyte human leukocyte antigen-DR; NK cells: natural killer cells; PELOD-2: PEdiatric Logistic Organ Dysfunction Score, version 2; PICU: pediatric intensive care unit; PIM2: pediatric index of mortality 2; TNF-a: tumor necrosis factor- $a$; Treg: regulatory T cells.
\end{abstract}

\section{Authors' contribution}

EJ and GM conceptualized and designed the study, and reviewed and revised each draft of the manuscript. SR collected clinical data, performed biological analysis, designed and conducted the statistical analysis, drafted the initial manuscript and reviewed and revised the manuscript. KK-D collected clinical data, reviewed and revised the manuscript. JD, MG and FV performed biological analysis, participated in statistical analysis, and reviewed and revised the manuscript. All authors read and approved the final manuscript.

\section{Author details}

${ }^{1}$ Hospices Civils de Lyon, Paediatric Intensive Care Unit, Mother and Children University Hospital, 59 Boulevard Pinel, 69500 Bron, France. ${ }^{2}$ Hospices Civils de Lyon, Immunology Laboratory, E. Herriot Hospital, 69003 Lyon, France. ${ }^{3}$ EA 7426, Pathophysiology of Injury-Induced Immunosuppression, University Claude Bernard Lyon 1, BioMérieux Hospices Civils de Lyon, E. Herriot Hospital, 69003 Lyon, France.

\section{Acknowledgements}

The authors acknowledge technical staff from Cellular Immunology Laboratory for realization of biological analysis. The authors also thank the Clinical Investigation Center, EPICIME - Lyon, for help in study's organization.

\section{Competing interests}

The authors declare that they have no competing interests.

\section{Availability of data and materials}

According to the French National Data Protection Commission, we are not authorized to provide the data.

\section{Ethics approval and consent to participate}

The study was approved by our Institutional Review Board (Comité de Protection des Personnes, Lyon Sud-Est II, number 2014-010-2, in accordance with Article L1121-1 of the French Public Health Code). According to legislation in place at the time of the study, this study required only the non-opposition of the study participants (written informed consent was not required). An information leaflet was systematically distributed to holders of parental authority. Participants and/or holders of parental authority could withdraw consent at any time. The study was registered: Pediatric Immune Response to Infectious Shock (PedIRIS). NCT02848144. https://www.clinicaltrials.gov/ct2/show/NCT02 848144?term $=$ pediris\&rank $=1$.

\section{Funding}

This study was supported by Hospices Civils de Lyon and University of Lyon. In addition, it was also funded by a research grant from the French Intensive Care Society (Société de Réanimation de Langue Française, SRLF) awarded to KKD.
The sponsors of the study had no role in study design, data collection, analysis and interpretation, or writing of the report.

\section{Publisher's Note}

Springer Nature remains neutral with regard to jurisdictional claims in published maps and institutional affiliations.

Received: 14 December 2017 Accepted: 3 March 2018

Published online: 13 March 2018

\section{References}

1. Schlapbach LJ, Straney L, Alexander J, MacLaren G, Festa M, Schibler A, et al. Mortality related to invasive infections, sepsis, and septic shock in critically ill children in Australia and New Zealand, 2002-13: a multicentre retrospective cohort study. Lancet Infect Dis. 2015;15(1):46-54.

2. Bilgin K, Yaramiş A, Haspolat K, Taş MA, Günbey S, Derman O. A randomized trial of granulocyte-macrophage colony-stimulating factor in neonates with sepsis and neutropenia. Pediatrics. 2001;107(1):36-41.

3. Hotchkiss RS, Monneret G, Payen D. Immunosuppression in sepsis: a novel understanding of the disorder and a new therapeutic approach. Lancet Infect Dis. 2013;13(3):260-8.

4. Venet F, Lukaszewicz A-C, Payen D, Hotchkiss R, Monneret G. Monitoring the immune response in sepsis: a rational approach to administration of immunoadjuvant therapies. Curr Opin Immunol. 2013;25(4):477-83.

5. Landelle C, Lepape A, Voirin N, Tognet E, Venet F, Bohé J, et al. Low monocyte human leukocyte antigen-DR is independently associated with nosocomial infections after septic shock. Intensive Care Med. 2010;36(11):1859-66.

6. Monneret G, Lepape A, Voirin N, Bohé J, Venet F, Debard A-L, et al. Persisting low monocyte human leukocyte antigen-DR expression predicts mortality in septic shock. Intensive Care Med. 2006;32(8):1175-83.

7. Hotchkiss RS, Monneret G, Payen D. Sepsis-induced immunosuppression: from cellular dysfunctions to immunotherapy. Nat Rev Immunol. 2013;13(12):862-74

8. Hotchkiss RS, Moldawer LL. Parallels between cancer and infectious disease. N Engl J Med. 2014;371(4):380-3.

9. Delano MJ, Ward PA. The immune system's role in sepsis progression, resolution, and long-term outcome. Immunol Rev. 2016;274(1):330-53.

10. Meisel C, Schefold JC, Pschowski R, Baumann T, Hetzger K, Gregor J, et al. Granulocyte-macrophage colony-stimulating factor to reverse sepsisassociated immunosuppression: a double-blind, randomized, placebocontrolled multicenter trial. Am J Respir Crit Care Med. 2009;180(7):640-8.

11. Hall MW, Knatz NL, Vetterly C, Tomarello S, Wewers MD, Volk HD, et al. Immunoparalysis and nosocomial infection in children with multiple organ dysfunction syndrome. Intensive Care Med. 2011;37(3):525-32.

12. Muszynski JA, Nofziger R, Greathouse K, Nateri J, Hanson-Huber L, Steele $L$, et al. Innate immune function predicts the development of nosocomial infection in critically injured children. Shock (Augusta Ga.). 2014:42(4):313-21.

13. Manzoli TF, Troster EJ, Ferranti JF, Sales MM. Prolonged suppression of monocytic human leukocyte antigen-DR expression correlates with mortality in pediatric septic patients in a pediatric tertiary Intensive Care Unit. J Crit Care. 2016;33:84-9.

14. Muszynski JA, Nofziger R, Greathouse K, Steele L, Hanson-Huber L, Nateri J, et al. Early adaptive immune suppression in children with septic shock: a prospective observational study. Crit Care Lond Engl. 2014;18(4):R145.

15. Wisgrill L, Groschopf A, Herndl E, Sadeghi K, Spittler A, Berger A, et al. Reduced TNF-a response in preterm neonates is associated with impaired nonclassic monocyte function. J Leukoc Biol. 2016;100(3):607-12.

16. Genel F, Atlihan F, Ozsu E, Ozbek E. Monocyte HLA-DR expression as predictor of poor outcome in neonates with late onset neonatal sepsis. J Infect. 2010;60(3):224-8.

17. Dellinger RP, Levy MM, Rhodes A, Annane D, Gerlach H, Opal SM, et al. Surviving Sepsis Campaign: international guidelines for management of severe sepsis and septic shock, 2012. Intensive Care Med. 2013;39(2):165-228. 
18. Goldstein B, Giroir B, Randolph A, International Consensus Conference on Pediatric Sepsis. International pediatric sepsis consensus conference: definitions for sepsis and organ dysfunction in pediatrics. Pediatr Crit Care Med J Soc Crit Care Med World Fed Pediatr Intensive Crit Care Soc. 2005;6(1):2-8

19. Shearer WT, Rosenblatt HM, Gelman RS, Oyomopito R, Plaeger S, Stiehm $E R$, et al. Lymphocyte subsets in healthy children from birth through 18 years of age: the pediatric AIDS clinical trials group P1009 study. J Allergy Clin Immunol. 2003;112(5):973-80.

20. Slater A, Shann F, Pearson G, Paediatric Index of Mortality (PIM) Study Group. PIM2: a revised version of the Paediatric Index of Mortality. Intensive Care Med. 2003;29(2):278-85.

21. Leteurtre S, Duhamel A, Deken V, Lacroix J, Leclerc F, Groupe Francophone de Réanimation et Urgences Pédiatriques. Daily estimation of the severity of organ dysfunctions in critically ill children by using the PELOD-2 score. Crit Care Lond Engl. 2015;19:324.

22. Trzeciak S, McCoy JV, Phillip Dellinger R, Arnold RC, Rizzuto M, Abate $\mathrm{NL}$, et al. Early increases in microcirculatory perfusion during protocoldirected resuscitation are associated with reduced multi-organ failure at $24 \mathrm{~h}$ in patients with sepsis. Intensive Care Med. 2008;34(12):2210-7.

23. Horan TC, Andrus M, Dudeck MA. CDC/NHSN surveillance definition of health care-associated infection and criteria for specific types of infections in the acute care setting. Am J Infect Control. 2008;36(5):309-32.

24. Demaret J, Walencik A, Jacob M-C, Timsit J-F, Venet F, Lepape A, et al. Inter-laboratory assessment of flow cytometric monocyte HLA-DR expression in clinical samples. Cytometry B Clin Cytom. 2013;84(1):59-62.

25. Venet F, Davin F, Guignant C, Larue A, Cazalis M-A, Darbon R, et al. Early assessment of leukocyte alterations at diagnosis of septic shock. Shock (Augusta Ga.). 2010;34(4):358-63.

26. Saison J, Maucort-Boulch D, Chidiac C, Demaret J, Malcus C, Cotte L, et al. Increased regulatory T-cell percentage contributes to poor CD4(+) lymphocytes recovery: a 2-year prospective study after introduction of antiretroviral therapy. Open Forum Infect Dis. 2015;2(2):ofv063.

27. de Jager W, te Velthuis H, Prakken BJ, Kuis W, Rijkers GT. Simultaneous detection of 15 human cytokines in a single sample of stimulated peripheral blood mononuclear cells. Clin Diagn Lab Immunol. 2003;10(1):133-9.

28. Döcke W-D, Höflich C, Davis KA, Röttgers K, Meisel C, Kiefer P, et al. Monitoring temporary immunodepression by flow cytometric measurement of monocytic HLA-DR expression: a multicenter standardized study. Clin Chem. 2005:51(12):2341-7.

29. Wong HR, Cvijanovich N, Wheeler DS, Bigham MT, Monaco M, Odoms K, et al. Interleukin-8 as a stratification tool for interventional trials involving pediatric septic shock. Am J Respir Crit Care Med. 2008;178(3):276-82.

30. Peronnet E, Nguyen K, Cerrato E, Guhadasan R, Venet F, Textoris J, et al. Evaluation of mRNA biomarkers to identify risk of hospital acquired infections in children admitted to paediatric intensive care unit. PLOS ONE. 2016;11(3):e0152388.
31. Monserrat J, de Pablo R, Diaz-Martín D, Rodríguez-Zapata M, de la Hera A, Prieto A, et al. Early alterations of B cells in patients with septic shock. Crit Care Lond Engl. 2013;17(3):R105.

32. Halstead ES, Carcillo JA, Schilling B, Greiner RJ, Whiteside TL. Reduced frequency of CD56 dim CD16 pos natural killer cells in pediatric systemic inflammatory response syndrome/sepsis patients. Pediatr Res. 2013;74(4):427-32.

33. von Muller L, Klemm A, Durmus N, Weiss M, Suger-Wiedeck H, Schneider $M$, et al. Cellular immunity and active human cytomegalovirus infection in patients with septic shock. J Infect Dis. 2007;196(9):1288-95.

34. Monneret G, Debard A-L, Venet F, Bohe J, Hequet O, Bienvenu J, et al. Marked elevation of human circulating CD4 + CD25 + regulatory T cells in sepsis-induced immunoparalysis. Crit Care Med. 2003;31(7):2068-71.

35. Drewry AM, Ablordeppey EA, Murray ET, Beiter ER, Walton AH, Hall MW, et al. Comparison of monocyte human leukocyte antigen-DR expression and stimulated tumor necrosis factor alpha production as outcome predictors in severe sepsis: a prospective observational study. Crit Care Lond Engl. 2016;20(1):334

36. Bo L, Wang F, Zhu J, Li J, Deng X. Granulocyte-colony stimulating factor (G-CSF) and granulocyte-macrophage colony stimulating factor (GMCSF) for sepsis: a meta-analysis. Crit Care Lond Engl. 2011;15(1):R58.

37. Gessler P, Pretre R, Bürki C, Rousson V, Frey B, Nadal D. Monocyte functionassociated antigen expression during and after pediatric cardiac surgery. J Thorac Cardiovasc Surg. 2005;130(1):54-60.

38. Hoffman JA, Weinberg KI, Azen CG, Horn MV, Dukes L, Starnes VA, et al. Human leukocyte antigen-DR expression on peripheral blood monocytes and the risk of pneumonia in pediatric lung transplant recipients. Transpl Infect Dis. 2004;6(4):147-55

39. Stolk RF, van der Poll T, Angus DC, van der Hoeven JG, Pickkers P, Kox M. Potentially inadvertent immunomodulation: norepinephrine use in sepsis. Am J Respir Crit Care Med. 2016;194(5):550-8.

40. Gouel-Chéron A, Allaouchiche B, Guignant C, Davin F, Floccard B, Monneret $\mathrm{G}$, et al. Early interleukin-6 and slope of monocyte human leukocyte antigen-DR: a powerful association to predict the development of sepsis after major trauma. PLoS ONE. 2012;7(3):e33095.

41. Field-Ridley A, Dharmar M, Steinhorn D, McDonald C, Marcin JP. ICUacquired weakness is associated with differences in clinical outcomes in critically ill children. Pediatr Crit Care Med J Soc Crit Care Med World Fed Pediatr Intensive Crit Care Soc. 2016;17(1):53-7.

42. Carcillo JA, Dean JM, Holubkov R, Berger J, Meert KL, Anand KJS, et al. Inherent risk factors for nosocomial infection in the long stay critically ill child without known baseline immunocompromise: a post hoc analysis of the crisis trial. Pediatr Infect Dis J. 2016;35(11):1182-6.

43. Pfortmueller CA, Meisel C, Fux M, Schefold JC. Assessment of immune organ dysfunction in critical illness: utility of innate immune response markers. Intensive Care Med Exp. 2017:5(1):49.

\section{Submit your manuscript to a SpringerOpen ${ }^{\odot}$ journal and benefit from:}

- Convenient online submission

- Rigorous peer review

- Open access: articles freely available online

- High visibility within the field

Retaining the copyright to your article

Submit your next manuscript at springeropen.com 